\title{
Regional education on endoscopic surgery using a teleconference system with high- quality video via the internet: Saga surgical videoconferences
}

\author{
Tatsuya Manabe ${ }^{1 *}$ (D, Mitsuhiro Takasaki ${ }^{2}$, Takao Ide ${ }^{1}$, Kenji Kitahara ${ }^{3}$, Seiji Sato ${ }^{3}$, Seiji Yunotani ${ }^{4}$, Yoshimi Hirohashi ${ }^{5}$, \\ Akihiro lyama ${ }^{6}$, Masahiko Taniguchi ${ }^{7}$, Toshiro Ogata ${ }^{7}$, Shuji Shimizu ${ }^{8}$ and Hirokazu Noshiro ${ }^{1}$
}

\begin{abstract}
Background: Effective education about endoscopic surgery (ES) is greatly needed for unskilled surgeons, especially at low-volume institutions, to maintain the safety of patients. We have tried to establish the remote educational system using videoconference system through the internet for education about ES to surgeons belonging to affiliate institutions. The aim of this manuscript was to report the potential to establish a comfortable remote educational system and to debate its advantages.

Methods: We established a local remote educational conference system by combining the use of a general web conferencing system and a synchronized remote video playback system with annotation function through a highspeed internet.

Results: During 2014-2019, we conducted 14 videoconferences to review and improve surgeons' skills in performing ES at affiliated institutions. At these conferences, while an uncut video of ES that had been performed at one of the affiliated institutions was shown, the surgical procedure was discussed frankly, and expert surgeons advised improvements. The annotation system is useful for easy, prompt recognition among the audience regarding anatomical structures and procedures that are difficult to explain verbally.
\end{abstract}

Conclusions: This system is of low initial cost and offers easy participation and high-quality videos. It would therefore be a useful tool for regional ES education.

Keywords: Endoscopic surgery, Videoconference, Remote, High-speed internet

\section{Background}

Endoscopic surgery (ES) - a minimally invasive surgery introduced during the 1990s-has become popular worldwide. In Japan, the number of ESs has rapidly increased, especially since being covered by insurance. To date, ES has been undertaken at most hospitals and

\footnotetext{
* Correspondence: manabe@cc.saga-u.ac.jp

'Department of Surgery, Faculty of Medicine, Saga University, 5-1-1 Nabeshima, Saga 849-8501, Japan

Full list of author information is available at the end of the article
}

medical centers [1]. However, there are still differences in short-term and long-term outcomes among institutions and surgeons, depending on their experience (based on the volume of ESs undertaken) and the training environment [2-4]. Because the complicated techniques used in ES necessitate long learning curves $[5,6]$, an effective educational system should be devised and systematically conducted for surgeons unskilled in ES procedures, especially at low-volume institutions, to ensure patients' safety. 
Various approaches to educating new and inexperienced surgeons regarding ES have been reported, including the use of textbooks, published papers, videos, simulators, surrogate animals, and cadavers [7, 8]. Among them, highquality videos of ES procedures, which allow surgeons to watch an operation recorded in progress, have great potential to enhance surgical education [9-12]. The conference, in which expert surgeons review ES videos and instruct the precise procedure to the audience, could not only improve the trainee's surgical skill and knowledge, but educate the conference participants as well.

In the past, the Saga University Department of Surgery sent medical/surgical staff to affiliated institutions to educate their surgeons and staff. However, there are three problems with that approach to ES education. First, most affiliated institutions are small or mediumsized, and in some, the volume of ES is too small for training and education. Second, an expert surgeon cannot always supervise ES performed by trainees in affiliated institutions. Third, surgeons belonging to affiliated institutions are difficult to gather in one place for an educational conference because of the location of the institution. Therefore, the education for ES procedure for surgeons at affiliated institutions of Saga University was the urgent necessity.

Teleconference system has been applied to medicine for more than 30 years [13]. With the development of information technology, some authors have reported the teleconference and/or telemedicine using transmitted moving images in the early stage $[14,15]$. However, it was impossible to avoid compression of images because of the limitation of transmitted information volume, resulting in decreasing the quality of moving images [16]. Therefore, the tele-education for ES could not has become popular. In 1999, Digital Video Transport System (DVTS), which is a remote conference system capable of transporting uncompressed high-quality videos without time delay or noise, was invented in Japan, and many remote conferences using DVTS has been conducted among leading institutions [17-20]. However, for a teleconference using DVTS, a special network condition, such as static IP address and 30Mbps high-speed band, needs to be established, and therefore small or medium-sized institutions are still difficult to easily join the teleconference with high-quality video,

Therefore, we planned more easily available surgical videoconferences using a teleconference system to assess the quality of ES performance and to educate the surgeons at each affiliated institution. We report the potential to establish a comfortable remote educational environment by combining the use of a general web conferencing system and a synchronized remote video playback system with annotation function that is shared via high-speed internet.

\section{Methods}

Our remote ES educational endeavor was conducted using two systems. One is a general web conferencing system, Vidyo $^{\circ}$ (Vidyo Inc., Hackensack, NJ, USA), whose main server has been installed at Kyushu University. The other is a web-based video playback system, JoinView, which is a system used for high-speed collaborative editing at multiple locations in the broadcasting industry. JoinView ${ }^{\circ}$ has been expanded for medical use by Saga University, Kyushu

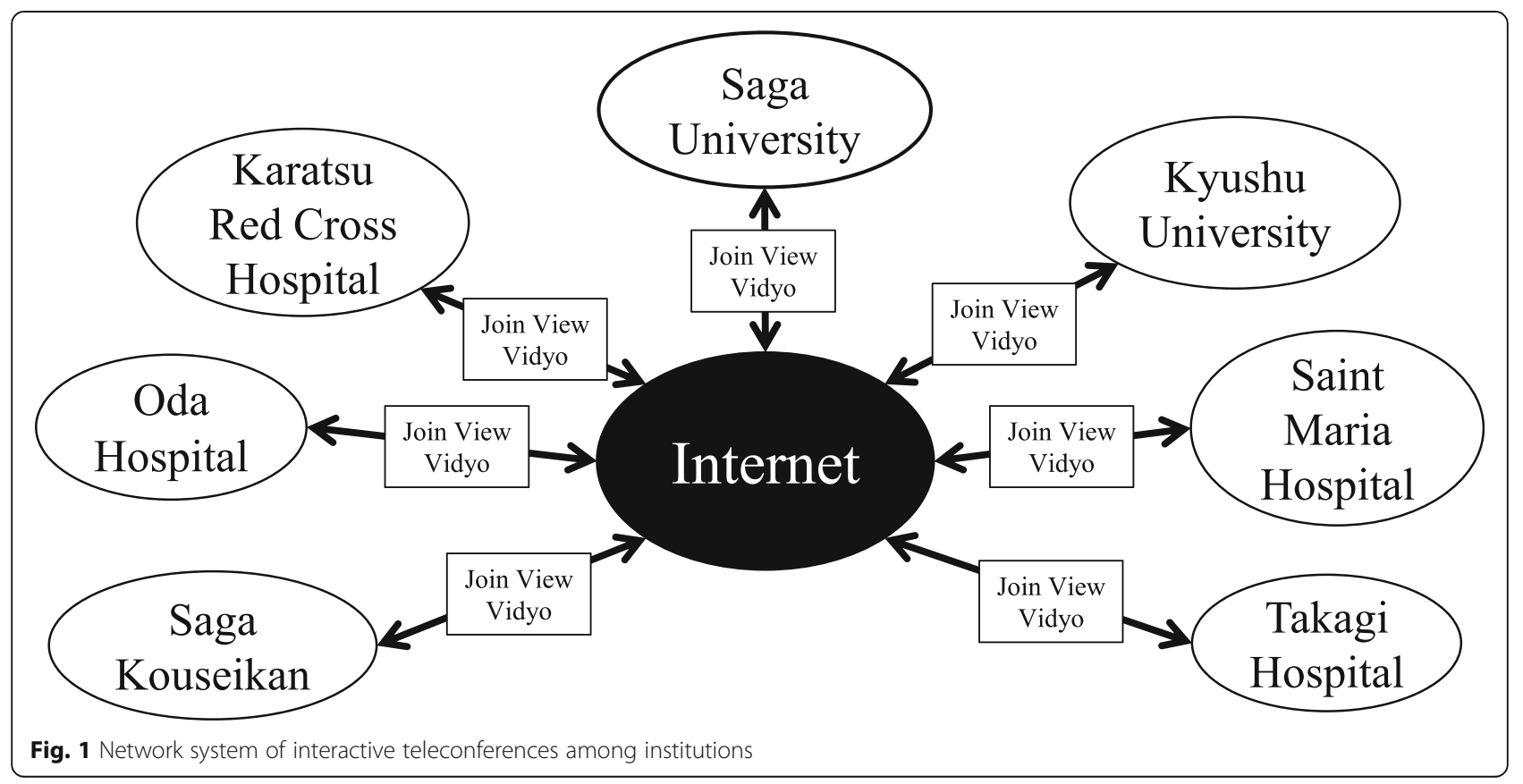




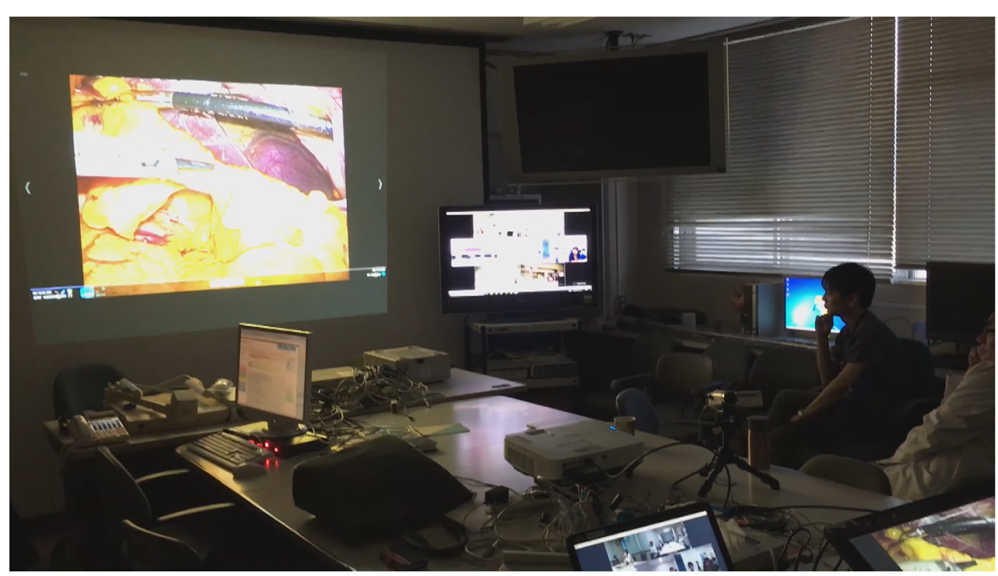

Fig. 2 Conference room at Saga University. Left monitor: Video of ES was played with surgeon's comment; Right monitor: View of the conference rooms at remote institutions

University and the developer Unixon Systems. Each institution was connected through commercial internet [21]. The interactive teleconferences involved recorded, uncut video with bidirectional discussion via JoinView and Vidyo (Fig. 1).

To prepare for a conference, the engineers first checked the transmission state, and one presenter belonging to one institution joining the conference uploaded a recorded uncut video of recently performed ES. At the conference, while showing a video, a presenter explains his procedures and proceeds with identifying the surgical anatomy. Experts then review the surgery and offer advice about the ES procedure (Fig. 2). Any participant at any institution engaged in the conference can freely ask questions about the surgery from anywhere on the network. Patients' names are never shown on the screen to protect their privacy, and all other private information is strictly controlled.

\section{Results}

Between September 2014 and September 2019, we conducted 14 videoconferences that reviewed the following laparoscopic surgical procedures: distal partial gastrectomy $(n=6)$, sigmoidectomy $(n=4)$, and low anterior resection of the rectum $(n=4)$. Details of the conferences are summarized in Table 1. For the first to sixth conferences, six institutions, including Kyushu University, were connected, and the senior surgeons belonging to one institution presented their uncut videos to assess the quality of ES at each institution. At the seventh conference, seven institutions were connected, and young surgeons volunteered to present their uncut videos for review and advice about their procedures. An annotation system, developed in JoinView, enabled dots, lines, and words to be described on the screen to clarify the verbal description. These annotations can be added from everywhere on the network (Fig. 3).

\section{Discussion}

Currently, ES has become the mainstream choice for minimally invasive gastrointestinal surgery in Japan. Many young surgeons are eager to improve their ES skill, resulting in more qualified surgeons entering the ranks of the skilled ES qualification system [22, 23]. Various meetings for reviewing videos-so-called video clinics-have been held for a fee or free under the sponsorship of surgical societies, ES-related corporations, and personal volunteers. However, many surgeons, especially surgeons belonging to local, small institutions, cannot easily participate in such meetings because of their daily work schedules, and the long distances and expenses involved in travel. Our teleconference system could save time and travel expenses for those busy doctors [24, 25],

Table 1 Details of the 14 Saga surgical videoconferences (2014-2019)

\begin{tabular}{llllll}
\hline No. & Year & Date & Presenter & Institution & Type of surgery \\
\hline 1 & 2014 & $9 / 30$ & Senior & Kouseikan & Distal gastrectomy \\
2 & & $12 / 2$ & Senior & Karatsu & Low anterior resection \\
3 & 2015 & $2 / 24$ & Senior & Takagi & Distal gastrectomy \\
4 & & $6 / 30$ & Senior & Oda & Distal gastrectomy \\
5 & & $10 / 27$ & Senior & Saga Univ. & Intersphincteric \\
& & & & & resection \\
6 & 2016 & $4 / 26$ & Senior & Kouseikan & Distal gastrectomy \\
7 & 2017 & $1 / 31$ & Young & Karatsu & Sigmoidectomy \\
8 & & $5 / 30$ & Young & Takagi & Low anterior resection \\
9 & & $9 / 26$ & Young & Oda & Low anterior resection \\
10 & 2018 & $2 / 6$ & Senior & Saint Maria & Distal gastrectomy \\
11 & & $6 / 5$ & Young & Saga Univ. & Sigmoidectomy \\
12 & & $10 / 2$ & Young & Kouseikan & Sigmoidectomy \\
13 & 2019 & $5 / 28$ & Young & Karatsu & Distal gastrectomy \\
14 & & $10 / 29$ & Young & Takagi & Sigmoidectomy \\
\hline
\end{tabular}




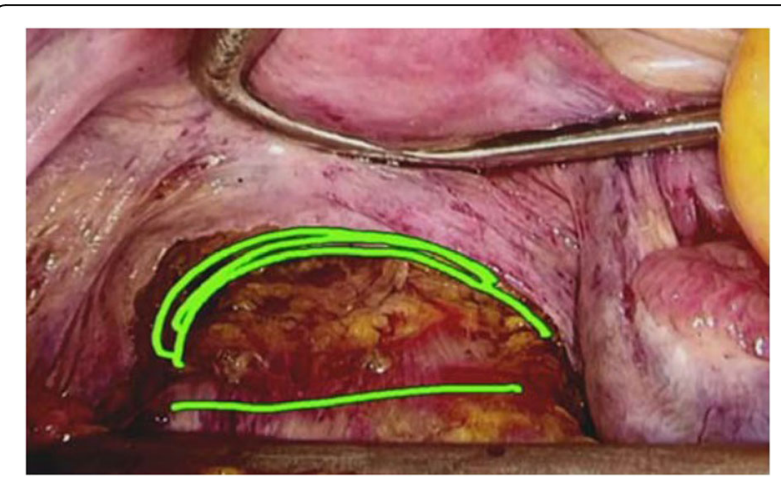

Fig. 3 Annotation system of dots, lines, and words that explain visually on the screen what may be described verbally. Annotations can be added from anywhere by anyone on the network allowing many more surgeons at various institutions to easily attend these educational meetings. Likewise, this conference system would be expected to be applied to the education for other complicated medical technique, such as microsurgery, robot-assisted surgery, endoscopic submucosal dissection, and so on.

Invention of DVTS, which could transfer uncompressed, high-quality video that is as clear as that obtained in the operating room, opened a new era for telemedicine, and many domestic and international teleconferences using DVTS have been successfully conducted among the leading institutions [17-20]. However, regional small or medium-sized institutions still could not join easily because of the special network setting for DVTS. Nowadays, several web conference systems, such as Vidyo and Zoom, have become easily available over commercial internet, but the videos brought from such systems are not suitable for surgical video conference in the absence of multiaccess handling and annotation system. Therefore, we tried to separately use a general web conference system and a synchronized remote video transfer system ensuring highquality images. We adopted JoinView as a video transfer system and Vidyo as a teleconference system. JoinView has several advantages as follows. It can be operated with a web browser and used with various computer operating systems because no special software is required. The highquality moving images provide clear views of the anatomy with its fine structures for the audience. Moreover, the anatomical structures and procedures are difficult to explain verbally, but by using the annotation system equipped in JoinView, the educator's verbal descriptions are easily and immediately understood by the audience.

Uncut videos have been used during these teleconferences because edited videos, which are useful for learning the basic procedure, usually do not cover procedures in their entirety, and there is no opportunity to ask questions. When uncut video is used via telecommunication, the observers' questions and any misunderstandings of the presenter can be addressed and clarified throughout the surgery. The ability of skilled surgeons to correct any mistakes or advice is useful not only for the presenter but for the audience as well. All expert surgeons who gave advice at our conferences were volunteers belonging to participated institutions.

As for initial investment, this system requires only common and widely available equipment, such as digital video cameras, personal computers and monitors, all usually available in most medical institutions. Moreover, the internet is economical and easy to access, and the Vidyo server at Kyushu University can be freely used for academic purposes. From the above requirement, various institutions could easily participant the teleconference with low cost.

\section{Conclusion}

We have developed and conducted regional surgical videoconferences using a broadband internet-based telecommunication system that can preserve the original quality of surgical video. This system comes at a low initial cost, promotes easy participation, and offers highquality video. We therefore believe that it would be a useful tool for regional education concerning ES.

\section{Abbreviations \\ ES: Endoscopic surgery; DVTS: Digital Video Transport System}

\section{Acknowledgments}

The authors are truly grateful for the technical expertise and cooperation of the engineering staff of Telemedicine Development Center of Kyushu University Hospital. We thank Nancy Schatken, BS, MT (ASCP), from Edanz Group (https://en-author-services.edanzgroup.com/), for editing a draft of this manuscript.

\section{Authors' contributions}

T. Manabe is the main author of this article and performed the data collection. MT1, TI, SS1, and HN contributed to the practice of the conference and reviewed the manuscript. KK, SS2, SY, YH, Al, MT2, and TO contributed to the practice of the conference. All authors have read and approved the final manuscript. (MT1 corresponding to Mitsuhiro Takasaki, MT2 corresponding to Masahiko Taniguchi, SS1 corresponding to Shuji Shimizu, SS2 corresponding to Seiji Sato).

Funding

There was no funding for this study.

Availability of data and materials

The author can confirm that all relevant data are presented within the manuscript.

\section{Ethics approval and consent to participate}

In this study, no private information and no samples gathered by human bodies were used, and therefore this study does not fall under Ethical Guidelines for Medical and Health Research Involving Human Subjects advocated by Ministry of Health, Labour and Welfare of Japan.

Consent for publication

Participants gave their consent for publication.

\section{Competing interests}

The authors declare no competing interests in association with the present study. 


\section{Author details}

'Department of Surgery, Faculty of Medicine, Saga University, 5-1-1 Nabeshima, Saga 849-8501, Japan. ${ }^{2}$ Saga University Organization for Genera Education, Saga University, 5-1-1 Nabeshima, Saga 849-8501, Japan. ${ }^{3}$ Department of Surgery, Saga Medical Center Koseikan, 400 Nakabaru, Kasemachi, Saga 849-8571, Japan. ${ }^{4}$ Department of Surgery, Japanese Red Cross Karatsu Hospital, 2430 Watada, Karatsu, Saga 847-8588, Japan. ${ }^{5}$ Department of Surgery, Takagi Hospital, 141-11 Sakemi, Okawa, Fukuoka 831-0016, Japan. ${ }^{6}$ Department of Surgery, Oda Hospital, 4306 Takatsuhara, Kashima, Saga 849-1311, Japan. ${ }^{7}$ Department of Surgery, Saint Mary Hospital, 422 Tsubukuhonmachi, Kurume, Fukuoka 830-8543, Japan. ${ }^{8}$ International Medical Department, Kyushu University Hospital, 3-1-1 Maidashi, Higashi-ku, Fukuoka 812-8582, Japan.

Received: 19 March 2020 Accepted: 28 August 2020

Published online: 24 September 2020

\section{References}

1. Shiroshita $H$, Inomata M, Bandoh $T$, Uchida H, Akira S, Hashizume M Yamaguchi S, Eguchi S, Wada N, Takiguchi S, leiri S, Endo S, Iwazaki M, Tamaki Y, Tabata M, Kanayama H, Mimata H, Hasegawa T, Onishi K, Yanaga K, Morikawa T, Terachi T, Matsumoto S, Yamashita Y, Kitano S, Watanabe M. Endoscopic surgery in Japan: the 13th national survey (2014-2015) by the Japan Society for Endoscopic Surgery. Asian J Endosc Surg. 2019;12:7-18.

2. Reames BN, Ghaferi AA, Birkmeyer JD, Dimick JB. Hospital volume and operative mortality in the modern era. Ann Surg. 2014;260:244-51.

3. Gietelink L, Henneman D, van Leersum NJ, de Noo M, Manusama E, Tanis PJ, Tollenaar RA, Wouters MW. Dutch Surgical Colorectal Cancer Audit Group. The influence of hospital volume on circumferential resection margin involvement: results of the Dutch Surgical Colorectal Audit. Ann Surg. 2016;263:745-50

4. Archampong D, Borowski D, Wille-Jørgensen P, Iversen LH. Workload and surgeon's specialty for outcome after colorectal cancer surgery. Cochrane Database Syst Rev. 2012;14. https://doi.org/10.1002/14651858.CD005391. pub3.

5. Wishner JD, Baker JW Jr, Hoffman GC, Hubbard GW 2nd, Gould RJ, Wohlgemuth SD, Ruffin WK, Melick CF. Laparoscopic-assisted colectomy. The learning curve. Surg Endosc. 1995;9:1179-83.

6. Miskovic D, Ni M, Wyles SM, Tekkis P, Hanna GB. Learning curve and case selection in laparoscopic colorectal surgery: systematic review and international multicenter analysis of 4852 cases. Dis Colon Rectum. 2012;55: 1300-10.

7. Palter VN, Grantcharov TP. Development and validation of a comprehensive curriculum to teach an advanced minimally invasive procedure: a randomized controlled trial. Ann Surg. 2012;256:25-32.

8. White SA, Satchidanand RY, French JJ, Tait IZ, Manas DM. A cadaver lab training facility to facilitate laparoscopic liver resection. Surg Laparosc Endosc Percutan Tech. 2014:24:357-60.

9. Green JL, Suresh V, Bittar P, Ledbetter L, Mithani SK, Allori A. The utilization of video technology in surgical education: a systematic review. J Surg Res. 2019;235:171-80

10. Singh $\mathrm{P}$, Aggarwal $\mathrm{R}$, Tahir M, Pucher PH, Darzi A. A randomized controlled study to evaluate the role of video-based coaching in training laparoscopic skills. Ann Surg. 2015;261:862-9.

11. Ibrahim AM, Varban OA, Dimick JB. Novel uses of video to accelerate the surgical learning curve. J Laparoendosc Adv Surg Tech A. 2016;26:240-2.

12. Prebay ZJ, Peabody JO, Miller DC, Ghani KR. Video review for measuring and improving skill in urological surgery. Nat Rev Urol. 2019;16:261-7.

13. DeBakey ME. Telemedicine has now come of age. Telemed J. 1995:1:3.

14. Gandsas A, Altrudi R, Pleatman M, Silva Y. Live interactive broadcast of laparoscopic surgery via the Internet. Surg Endosc. 1998;12:252-5.

15. Malassagne B, Mutter D, Leroy J, Smith M, Soler L, Marescaux J. Teleeducation in surgery: European Institute for Telesurgery experience. World J Surg. 2001;25:1490-4.

16. Demartines N, Mutter D, Vix M, Leroy J, Glatz D, Rösel F, Harder F, Marescaux J. Assessment of telemedicine in surgical education and patient care. Ann Surg. 2000;231:282-91.

17. Shimizu S, Nakashima N, Okamura K, Hahm JS, Kim YW, Moon BI, Han HS, Tanaka M. International transmission of uncompressed endoscopic surgery images via superfast broadband Internet connections. Surg Endosc. 2006;20: 167-70.
18. Shimizu S, Nakashima N, Okamura K, Han HS, Tanaka M. Telesurgery system with original-quality moving images over high-speed Internet: expansion within the Asia-Pacific region. J Laparoendosc Adv Surg Tech A. 2007;17: $673-8$.

19. Hahm JS, Lee HL, Kim SI, Shimizu S, Choi HS, Ko Y, Lee KG, Kim TE, Yun JW, Park YJ, Naoki N, Koji O. A remote educational system in medicine using digital video. Hepatogastroenterology. 2007;54:373-6.

20. Shimizu S, Nakashima N, Okamura K, Tanaka M. One hundred case studies of Asia-Pacific telemedicine using a digital video transport system over a research and education network. Telemed J E Health. 2009;15:112-7.

21. Kudo K, Antoku Y. Telemedicine Conferencing An Introductory Guide for Engineers. 2017; http://nuhc.jp/Portals/0/images/activity/report/sgst_ category/globalization/guide.pdf.

22. Sakai Y, Kitano S. Practice guidelines on endoscopic surgery for qualified surgeons by the endoscopic surgical skill qualification system. Asian J Endosc Surg. 2015;8:103-13.

23. Mori T, Kimura T, Kitajima M. Skill accreditation system for laparoscopic gastroenterologic surgeons in Japan. Minim Invasive Ther Allied Technol. 2010;19:18-23.

24. Wootton R, Bahaadinbeigy K, Hailey D. Estimating travel reduction associated with the use of telemedicine by patients and healthcare professionals: proposal for quantitative synthesis in a systematic review. BMC Health Serv Res. 2011;11:185.

25. Shimizu S, Ohtsuka T, Takahata S, Nagai E, Nakashima N, Tanaka M. Remote transmission of live endoscopy over the Internet: Report from the 87th Congress of the Japan Gastroenterological Endoscopy Society. Dig Endosc. 2016:28:92-7.

\section{Publisher's Note}

Springer Nature remains neutral with regard to jurisdictional claims in published maps and institutional affiliations.

Ready to submit your research? Choose BMC and benefit from:

- fast, convenient online submission

- thorough peer review by experienced researchers in your field

- rapid publication on acceptance

- support for research data, including large and complex data types

- gold Open Access which fosters wider collaboration and increased citations

- maximum visibility for your research: over $100 \mathrm{M}$ website views per year

At $\mathrm{BMC}$, research is always in progress.

Learn more biomedcentral.com/submission 